Juha Leppämäki

\title{
ALTERNATIVE ACCESS - VAIHTOEHTOINEN SAATAVUUS MONEN KEINON KOKONAISUUS
}

\author{
Kirjastoaineistojen vaihtoehtoinen saatavuus tuli Suomessa \\ ajankohtaiseksi erityisesti viime vuonna, kun neuvottelut \\ FinELib-kirjastokonsortion ja tiedekustantaja Taylor \& Fran-
} cisin kanssa kariutuivat. Sen seurauksena yliopisto- ja korkeakoulukirjastoilta katkesi pääsy Taylor \& Francisin -lehtiin. Vaihtoehtoisella saatavuudella (alternative access) tarkoitan tässä yhteydessä tapoja saada käyttöön artikkeleita, jotka ovat kus-

tantajan maksumuurin takana.

$\mathrm{F}$ inELib-neuvottelujen kariutumisen taustalla ovat tieteellisen julkaisutoiminnan nykyisen mallin ongelmat ja käynnissä oleva muutosprosessi kohti open access -julkaisemista. Suurten tiedekustantajien kustantamien tieteellisten kausijulkaisujen hinnat yliopistoille ovat olleet jatkuvassa nousussa (ks. esim. Kustantajahintatiedot Suomessa 2010-20 I7). Suomessa FinELib-konsortion yhtenä tavoitteena neuvotteluissa kustantajien kanssa onkin, että tieteellisten julkaisujen hintojen pitää olla kohtuullisia. Kyse ei kuitenkaan ole ainoastaan saatavuuden hinnasta. Toinen puoli on open access -julkaisemisen hinta. Finelibin tavoitteiden mukaan siirtyminen avoimeen julkaisemiseen pitää toteuttaa ilman lisäkustannuksia. Toisin sanoen sellainen tilanne, jossa verorahoin ensin maksetaan julkaisumaksu, jotta artikkeli saadaan avoimeksi ilman, että tätä huomioidaan tilausmaksuissa, ei ole hyväksyttävä. Ei siis neuvotella ainoastaan pääsyn hinnasta, vaan myös julkaisemisen hinnasta.

Suomi ei tietenkään ole yksin tässä tilanteessa, vaan samat kysymykset ovat ajankohtaisia muuallakin maailmassa. Elsevierin kanssa sopimusta ei ole syntynyt Saksassa 2017 eikä Ruotsissa 20 I 8. Samalla tavalla vaatimus avoimesta tiedejulkaisemista on kansainvälinen, ja Suomen lisäksi Euroopassa on laajalti osoitettu tukea Plan S:lle, jonka päämääränä on tehdä Plan $S$-koalitioon kuuluvien rahoittajien rahoittama tiedejulkaiseminen avoimesti saatavaksi.

Saatavuudesta ja avoimesta julkaisemisesta neuvoteltiin Suomessa vuoden 20I 8 lopussa sekä Wileyn että Taylor $\&$ Francisin kanssa. Sopimukset päättyivät jo vuoden 2018 lopussa, mutta neuvotteluita jatkettiin vuoden 2019 
alussa eikä pääsy artikkeleihin katkennut heti. Wileyn kanssa jatkettiin lyhytaikaisella sopimuksella vuoden 2019 loppuun. Uusi sopimus saatiin neuvoteltua vuoden 2020 alussa. Taylor \& Francisin kanssa sopimusta ei syntynyt ja pääsy lehtiin katkesi helmikuussa 20I9. Konsortiotilaukseen kuului I 807 kausijulkaisunimekettä.

\section{Valmistautuminen pääsyn katkeamiseen}

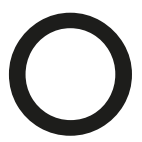
sallistuin Helsingin yliopiston kirjastossa alternative access -työryhmän toimintaan.

Viestintä asiakkaille aloitettiin jo ennen pääsyn katkeamista. Varoitimme etukäteen, että neuvottelut ovat vaikeassa tilanteessa ja pääsy saattaa lakata näiden kustantajien lehtiin. Kehotimme tutkijoita ottamaan talteen tarvitsemansa artikkelit. Tässä yhteydessä piti myös muistuttaa siitä, että lisenssiehtojen mukaan ei ole sallittua systemaattisesti ladata kaikkea sisältöä.

Osana viestintää kirjasto loi alternative access -verkkosivun. Myös FinELib teki alternative access -sivun aineistoneuvotteluista kertoville sivuilleen. Osin mallia otettiin ulkomaisista yliopistokirjastoista, joiden sivuja tutkittiin silloin, kun Suomessa varauduttiin pääsyn katkeamiseen. Alternative access -sivuilla on lyhyesti tietoa neuvottelutilanteesta sekä link- kejä eri työkaluihin ja hakukoneisiin. Tärkeä on myös tieto, että asiakas voi aina voi ottaa yhteyttä kirjastoon, joka auttaa selvittämään, miten tarvittavat artikkelit voidaan saada käyttöön.

Asiakkaat pyrittiin ohjaamaan alternative access -sivulle. Sivulle oli linkki kirjaston Helka-tietokannan etusivulla. Taylor $\&$ Francisin lehtien kohdalle Helkan saatavuustietoihin tehtiin merkintä siitä, että pääsy on rajattu ja linkki ohjasi alternative access -sivulle.

\section{Miten Helsingin yliopiston \\ kirjastossa on toteutettu vaihtoehtoista saatavuutta?}

Käytössä on pääasiallisesti kolme tapaa hankkia artikkeleita. Ensimmäinen tapa on perinteinen kaukopalvelu. Toinen tapa on artikkelien open access -versioiden löytäminen. Tällä tarkoitan laillisesti saatavilla olevia versioita yliopistojen ja muiden instituutioiden julkaisuarkistoista (ns. green open access). Kolmas tapa on artikkelien ostaminen artikkeli kerrallaan. Artikkelien ostamiseen Helsingin yliopiston kirjasto on käyttänyt Copyright Clearance Centerin Get It Now -palvelua. Lisäksi on mainittava, että esimerkiksi Ebscon ja Proquestin laajoissa lehtitietokannoissa on saatavilla niitä Taylor \& Francisin lehtiä, joihin pääsy on katkennut. Monesti paketteihin kuuluvissa lehdissä on tosin esimerkiksi 
vuoden embargo, mutta kaikki saatavuus auttaa tässä tilanteessa. Seuraavaksi tarkastellaan lähemmin kolmea tapaa hankkia artikkeleita.

\section{Kaukopalvelu ja resurssien jakaminen}

On tärkeä huomata, että kaukopalvelussa konsortiolla on käytössä enemmän resursseja kuin sen yksittäisillä jäsenkirjastoilla. Kun pääsy katkesi, se ei koskenut kaikkea Taylor \& Francisin aineistoa. Kullakin kirjastolla oli niin sanotut core- eli ydin-tilaukset, joihin sopimuksen mukaan on pitkäaikaiskäyttöoikeus. Pitkäaikaiskäytöllä (perpetual access) tarkoitetaan sitä, että pääsy maksettuun aineistoon säilyy tilauksen päättymisen jälkeen. Core-tilauksissa on kyse niistä lehtinimekkeistä, joihin kullakin kirjastolla oli tilaus voimassa silloin, kun laajemman lehtikokoelman sisältävään konsortiosopimukseen mentiin mukaan.

Pääsy näihin lehtiin säilyi niiden vuosien osalta, jolloin tilaus oli ollut voimassa. Konsortiossa mukana olevilla kirjastoilla oli kullakin erilainen valikoima core-tilauksia. Vaikka kirjastojen core-tilauksissa oli samoja lehtiä, oli kullakin yliopistolla myös huomattava osa eri lehtiä riippuen yliopiston painoalueista. Tämän seurauksena kirjastoilla on konsortiotasolla tarkasteltuna suhteellisen kattava pääsy vanhoihin vuosikertoihin aina vuoden 20 I 8 loppuun asti, vaikka yksittäisellä kirjastolla on pääsy vain sen omiin core-tilauksiin. Kaiken kaikkiaan $38 \%$ lehdistä
(689/1807 lehteä) oli jonkin konsortion kirjaston core-tilauksia. Tässä tilanteessa korostuu perinteisen kirjastojen välisen kaukopalvelun merkitys. Voimme toimittaa artikkelikopioita vanhoista vuosikerroista toisten kirjastojen asiakkaille kaukopalvelun kautta. Ongelmana kuitenkin ovat vuoden 20 I 8 jälkeen julkaistut artikkelit. Toki kaukopalvelu voi tilata uudempia artikkeleita ulkomailta.

\section{Open access -versioiden löytäminen}

Open access on keskeinen teema lehtineuvotteluissa ja se on keskeinen elementti myös vaihtoehtoisessa saatavuudessa. Kirjaston alternative access -sivulla on listattu useita työkaluja ja hakukoneita, joilla open access -versioita artikkeleista voi etsiä. Samoja työkaluja voivat käyttää sekä kirjaston henkilökunta että asiakkaat.

\section{Selainlisäosat}

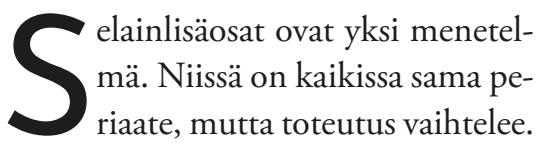
Esimerkiksi Open Access Buttonia voi käyttää joko hakulaatikon kautta tai selainlisäosana, joka tarkistaa onko open access -versiota saatavilla julkaisuarkistoissa. Selainlisäosana OA Button toimii niin, että maksumuuriin törmätessään käyttäjä voi napauttaa $\mathrm{OA}$ Buttonia, joka etsii sitten open access -version sivulla olevasta artikkelista. OA Buttonin erikoisuutena on se, että se voi auttaa hankkimaan open access 


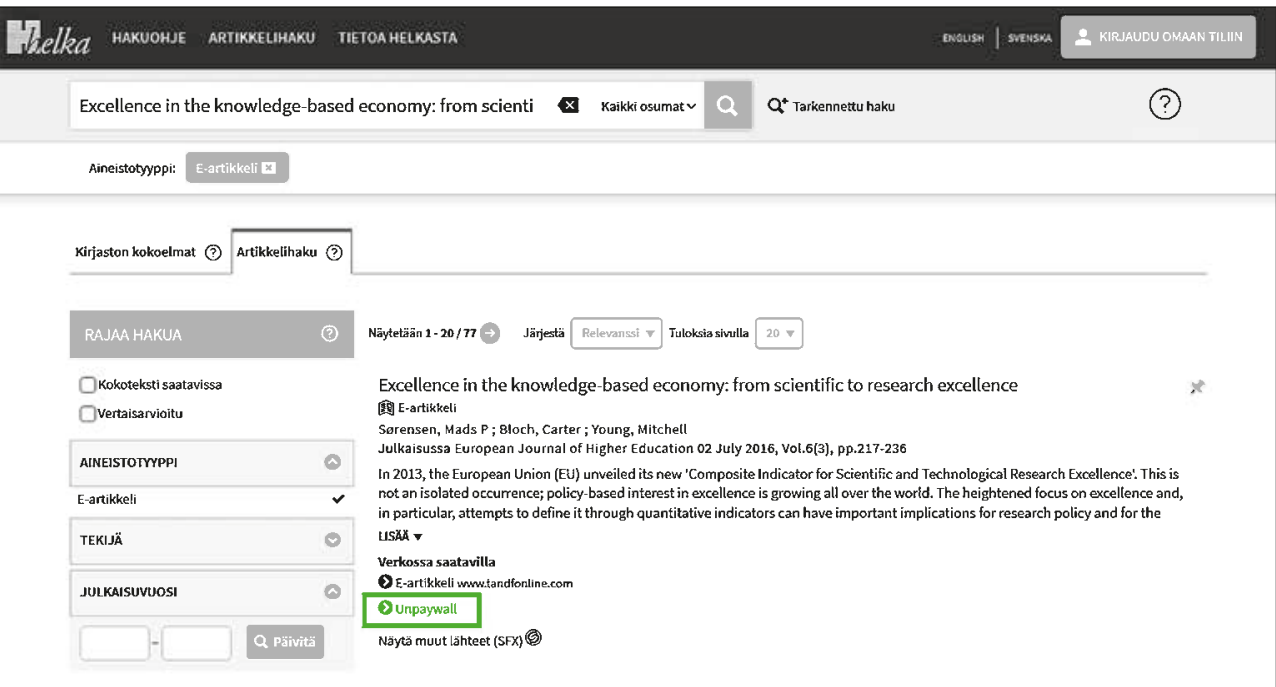

-version pyytämällä artikkelin tekijää tallentamaan artikkelin julkaisuarkistoon, mikäli open access -versiota ei löydy. Tällöin käyttäjän pitää kirjautua ja antaa sähköpostiosoite sekä kertoa, miksi tarvitsee artikkelin.

Unpaywall on suoraviivaisesti toimiva selainlisäosa, joka ilmoittaa, mikäli sivulla näkyvä artikkeli on saatavilla open access -versiona. Selainlisäosan lisäksi Unpaywall tarjoaa myös muita mahdollisuuksia kirjastoille. Helsingin yliopiston kirjastossa Unpaywall on aktivoitu kirjaston SFXlinkityksessä. Artikkelihaun tuloksissa näkyy Unpaywall-linkki, joka ohjaa käyttäjän suoraan julkaisuarkistossa olevaan vaihtoehtoiseen versioon, mikäli sellainen on saatavilla.

Muita selainlisäosia ovat esimerkiksi Lazy Scholar ja Kopernio, jotka toimivat edellisten tapaan eli etsivät open access -versioita artikkeleista. Ne osaavat linkittää myös lisensoituihin aineistoihin käyttäjän instituution perusteella. Lazy Scholarissa on myös ominaisuuksia esimerkiksi altmetriikkaan ja viittausten tekemiseen. Lazy Scholar luo käyttäjälle tunnuksen ja kerää historiaa hauista. Tällä perusteella se voi suositella muita artikkeleita samasta aiheesta. Kopernio on Clarivate Analyticsin selainlisäosa, jonka käyttäminen vaatii kirjautumista ja käyttäjätunnuksen luomista.

\section{Hakupalvelut}

Clainlisäosien lisäksi on myös hakupalveluita, joista voi kerralla hakea tuhansista lähteistä haravoituja open access -aineistoja. Alternative access -tarkoituksiin hyviä ovatkin sellaiset palvelut, jotka kokoavat yhteen tietoja eri yliopistojen julkaisuarkistoista ja open access -lehdistä. Esimerkiksi Core on voittoa tavoittelematon brittiläinen palvelu, jonka ideana on kerätä open access -artikkeleita julkaisuarkistoista ja lehdistä ympäri maailmaa, ja tehdä ne helposti löydettäviksi yhdestä paikasta. Tällä hetkellä palvelussa on haettavissa yli I 35 miljoonaa artikkelia. Coren dataa käyttää muun muassa tutkijoiden avuksi suunniteltu tekoäly Iris.ai.

Toinen hakupalvelu on Base, Biele- 
feldin yliopiston kirjaston ylläpitämä hakukone, johon on indeksoitu yli I 50 miljoonaa dokumenttia. Näistä noin $60 \%$ on open access -dokumentteja. Palvelu sisältää siis myös aineistoa, joka ei ole avoimesti käytettävissä. EU:n rahoittaman avoimen julkaisemisen infrastruktuurin, Openaire:n, palveluihin sisältyy hakuportaali, jossa on tällä hetkellä haettavissa yli 3 I miljoonaa dokumenttia. Tiedot kerätään useista julkaisuarkistoista ja lehdistä.

Hakupalvelut ovat ehkä parempia silloin, kun yrittää hakea avoimesti saatavilla olevaa aineistoa jostakin aiheesta, kun taas lisäosat ovat käytännöllisiä silloin, kun käyttäjä törmää maksumuuriin ja haluaa tietää, onko kyseinen artikkeli saatavilla open access -versiona. Yksittäisten artikkelien tarkistaminen hakupalveluiden avulla on toki mahdollista ja toimii hyvin.

\section{Artikkeli kerrallaan}

Läheskään kaikki artikkelit eivät tietenkään ole saatavilla open access -versioina. Samaan aikaan tutkijat ja opiskelijat odottavat, että kirjasto järjestää pääsyn tietoaineistoihin. Pääsyn katkettua Taylor \& Francisin lehtiin, töön Get It Now -artikkelienvälityspaltoön Get It Now -artikkelienvälityspalvelun vastatakseen tähän tarpeeseen.

Get It Now'n etu on se, että asiakkaat voivat käyttää sitä itsepalveluna Helkan artikkelihaun kautta. Kirjasto aktivoi sFX-linkityspalvelussa kaiken kaikkiaan yli 500 Taylor \& Francisin lehtiä, mukaan lukien edellä mainitut core-tilaukset sekä käyttötilastojen perusteella eniten luetut lehdet. Get It Now -vaihtoehto tulee näkyviin valikoitujen lehtien artikkeleille, kun muuta kokotekstisaatavuutta ei ole. Käyttö on rajattu Helsingin yli-

Towards greater understanding of success and survival of lean systems

专害E-artikkeli

Taylor, Andrew; Taylor, Margaret; Mcsweeney, Andrew

Julkaisussa International Journal of Production Research 01 January 2013, p. 1-24

The purposes of this research are to remove some of the confusion surrounding the characterisation of lean systems; to delve deeper into the human issues associated with lean; and to explore the complexity of an established lean system to identify issues which affect its success and ongoing continuance. Using the mixe LISÄÄ $\nabla$

HELSINGIN YLIOPISTON KIRJASTO LINKITYSPALVELU

Leke: Towards greater understanding of success and survival of lean system

Lähde: International journal of production research [0020-7543] [Peer Reviewed] Taylor Vuosi:2013

¿ Elektronista kokotekstiä ei ole saatavissa.

Paikanna kokotekstin kopio DOl-palvelulla Huomautus:Kokotekstiin ei ole ehkä lukuoikeutta

(]) Tarkista saatavuus Helka

D) Tarkista saatavuus HELDA - Helsingin yliopiston julkaisuarkisto

Dokumenttipalvelu CCC Get It Now Taylor and Francis

Dokumenttipalvelu HUPS-aineistotỉlaus HY/HYKS -henkilöstölle

Ei kokotekstiä? Tilaa kaukopalvelun kautta

E-lehdet ISI's Journal Citation Report (JCR) Science Edition 2017 Release 


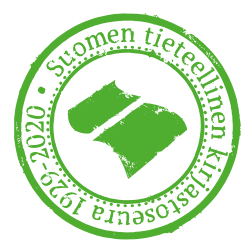

opiston henkilökunnalle ja opiskelijoille sähköpostiosoitteen perusteella, ja artikkelit toimitetaan asiakkaan sähköpostiin. Get It Now laskuttaa toimitetut artikkelit kirjastolta. Käyttöehdot rajaavat artikkelin henkilökohtaiseen käyttöön, ja myös artikkelin säilytysaika on rajallinen.

SFX:ssä on mahdollista rajata, mitkä lehdet ja vuosikerrat ovat palvelun piirissä. Get It Now -palvelun hallintaliittymässä voidaan rajata rahan käyttöä kokonaisuudessaan tai yhden artikkelin maksimihintaa. Voidaan myös asettaa aikarajauksia yhden käyttäjän tilauksille. Kaiken kaikkiaan palvelu on varsin joustavasti mukautettavissa kirjaston tarpeita vastaavaksi.

Toinen tapa käyttää Get It Now -palvelua on kaukopalvelun apuvälineenä eli, niin että asiakas pyytää artikkelia ja kirjasto tilaa sen.

\section{Vaihtoehtoinen saatavuus kokonaisuutena}

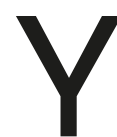

htä ratkaisua vaihtoehtoiseen saatavuuteen ei ole, vaan sitä on käytännössä toteutettava usealla eri tavalla, joilla kaikilla on etunsa ja puutteensa. Open access -artikkelien etsiminen on hyvin linjassa aineistoneuvottelujen päämärän, avoimen saatavuuden lisäämisen, kanssa. Ja mitä enemmän open access -julkaiseminen ja rinnakkaistallentaminen edistyvät eri maissa, sitä enemmän tätä kautta löytyy maksutonta vaihtoehtoista saatavuutta. Toisaalta julkaisuarkistoihin tallennetut open access -versiot harvemmin ovat kustantajan versioita. Kuitenkin, jos kyseessä on vertaisarvioitu käsikirjoitus, niin ainakin informaatiosisällön pitäisi olla sama kuin kustantajan versiossa, vaikka sivunumerointi ja muut yksityiskohdat eivät olisikaan.

Kirjastojen resurssien jakamisessa ongelmana ovat kaukopalvelua rajoittavat lisensseihin liittyvät ja lailliset rajoitukset, joiden vuoksi asiakkaille voidaan toimittaa vain paperikopioita artikkeleista. Toisaalta kaukopalvelu on perinteistä kirjastojen välistä yhteistyötä ja kirjastoilla on valmis hyvin toimiva prosessi kaukopalvelulle. Kirjastojen välisen yhteistyön merkitys korostuu poikkeuksellisessa tilanteessa, jossa pääsy katkeaa useisiin satoihin lehtiin.

Artikkelien ostamisen etuna on se, että käyttäjät saavat tarvitsemansa artikkelit nopeasti ja sähköisessä muodossa. Tämä kuitenkin maksaa, joten loppujen lopuksi kirjasto päätyy kuitenkin maksamaan kustantajalle pääsystä, vaikkakin artikkeli kerrallaan. Voidaan ajatella, että se ei ole neuvottelujen edistämisen kannalta toivottavaa. Tätäkin palvelua kuitenkin tarvitaan, jotta käyttäjät voivat edelleen luottaa siihen, että kirjaston kautta artikkelit on mahdollista saada myös poikkeustilanteessa.

Asiakkaat voivat tietenkin etsiä, ja etsivätkin, vaihtoehtoista saatavuutta kirjastosta riippumatta. Kirjaston luoman alternative access -sivun tarkoituksena onkin tarjota välineitä ar- 
tikkelien omatoimiseen löytämiseen. Tutkijat voivat pyytää artikkeleita suoraan kirjoittajilta tai sellaiselta kollegalta, jolla on lisensoitu pääsy. Yleensä lisenssit sallivat sen, että käyttäjä, jolla on pääsy maksulliseen aineistoon voi tieteellisen kommunikaation puitteissa jakaa artikkeleita pienessä määrin. Tarkoitusta varten on keksitty aihetunniste \#ICanHazPDF, jota käytetään Twitterissä artikkeleiden pyytämiseen.

Kirjastossa näemme vain sen käytön ja ne kyselyt, jotka kirjastolle tulevat. Tutkijoiden keskinäinen kommunikaatio ja jakaminen, joka ei kulje kirjaston kautta, jää näkymättömiin. FinELib on suunnitellut kyselyä Taylor \& Francis -katkon vaikutuksista Suomessa. Sen toteutuessa voidaan tulevaisuudessa saada tietoa siitä, millä eri tavoilla käyttäjät ovat maksumuurin takaisia artikkeleita saaneet.

Ruotsissa on jo tehty kysely Elsevier-katkon vaikutuksesta. Siellä $23 \%$ vastaajista oli saanut artikkelin kirjaston kautta, $22 \%$ kollegan kautta ja $22 \%$ artikkelin tekijän kautta. Iso osa (42\%) oli löytänyt artikkeleita online. Kuitenkin vain neljänneksellä oli edellä esiteltyjä selainlisäosia asennettuna. Online-lähteissä erottui ResearchGate

(24\%). (Olsson ym. 2019.)

Ovatko kirjastot sitten epäonnistuneet, jos vain $23 \%$ kertoo saaneensa artikkelin kirjaston kautta? Mielestäni eivät, koska on selvää, ettei kirjasto voi neuvottelujen kariutumisen tapaisessa poikkeustilanteessa toimittaa kaikkia asiakkaiden tarvitsemia artikkeleita. Olennaisempaa onkin, että kirjasto pystyy ohjaamaan asiakkaita vaihtoehtoisten saatavuuskeinojen pariin ja opettamaan niiden käytössä.

Artikkeli perustuu tekijän sTKs:n Pysy pinnalla -seminaarissa 24.10.2019 pitämään esitelmään.

\section{Lähteet:}

Kustantajahintatiedot Suomessa 2010-2017, Opetus- ja kulttuuriministeriö, http://urn.fi/urn:nbn:fi:csc-kata2017061 3 I04454620616.

Olsson, Lisa, Camila Hertil Lindelöw, Frida Jakobsson \& Lovisa Österlund (2019). Consequences of Sweden Cancelling Elsevier. Zenodo. HTTP://DOI.ORG/IO.528I/ZENODO.3259809.

\section{Tietoa kirjoittajasta}

JUHA LEPPÄMÄKI

Helsingin yliopiston kirjasto

juha.leppamaki@helsinki.fi 